\title{
The outcome of surgery in 668 patients with acromegaly using current criteria of biochemical 'cure'
}

\author{
Panagiotis Nomikos, Michael Buchfelder and Rudolf Fahlbusch
}

Department of Neurosurgery, University of Erlangen-Nürnberg, Erlangen, Germany

(Correspondence should be addressed to P Nomikos, who is now at Department of Neurosurgery and Gamma Knife Radiosurgery, HYGEIA Hospital 4, Erythrou Stavrou E Kifisias Ave, 15123 Maroussi, Greece; Email: nomikosp@otenet.gr)

\begin{abstract}
Background and aim: The aim of this study was to illustrate the present role of transsphenoidal surgery as primary therapy in GH-secreting adenomas, and to compare the results concerning control of disease with previous series using older criteria of cure.

Method: We report on a consecutive series of 688 acromegalic patients treated over a time period of 19 years. Biochemical cure was defined as normalisation of basal GH level, suppression of GH levels to below $1 \mathrm{ng} / \mathrm{ml}$ during an oral glucose load and normalisation of IGF-I levels. Of the 506 patients undergoing primary transsphenoidal surgery, a total of $57.3 \%$ postoperatively fulfilled the criteria used.

Results: The rate of biochemical 'cure' correlated with the magnitude of the initial GH levels, the tumour size and invasion. The overall complication rate was below $2 \%$. Mortality in this series was $0.1 \%$ ( 1 of 688 ). During a follow-up period of 10.7 years only two recurrences $(0.4 \%)$ occurred. However, in the patients treated by transcranial surgery and by repeat surgery the cure rate was found to be relatively low (5.2 and $21.3 \%$ respectively).

Conclusions: These data suggest that surgery remains with very few exceptions the primary treatment of acromegaly for (i) a high cure rate, (ii) low morbidity, (iii) low recurrence rate and (iv) immediate decline of GH. Based on current criteria of cure, recurrences are uncommon. However, cure by surgery alone is improbable in patients harbouring extended, invasive tumours with high secretory activity, in whom further adjuvant treatment is mandatory.
\end{abstract}

European Journal of Endocrinology 152 379-387

\section{Introduction}

Acromegaly is a rare but very serious condition usually caused by a growth hormone $(\mathrm{GH})$-producing pituitary adenoma. Ectopic GH or GH-releasing hormone production or a pituitary carcinoma may very infrequently also cause acromegaly. Several retrospective cohort studies suggest that mortality in acromegaly is at least twice of that in the general population $(1-4)$. The cause of death is most commonly a vascular accident, but significant increases have been reported for both respiratory disorders and malignancies. These studies have also demonstrated that a reduction of $\mathrm{GH}$ levels significantly lowered mortality and that mortality rates similar to those of the general population are restored once remission is induced. Partial reduction of GH levels has been proven to be inadequate to restore normal life expectancy $(1,5)$. Therefore, aggressive management to lower serum GH levels is necessary once the diagnosis has been confirmed. Depot somatostatin analogues are now increasingly being prescribed as adjuvant or even primary therapy for the treatment of acromegaly. Studies have shown them to be both effective and safe with endocrinological remission achieved in up to $60 \%$ of cases (6-9). The newly developed $\mathrm{GH}$ receptor antagonist pegvisomant seems to be able to normalise insulin-like growth factor (IGF)-I in up to $97 \%$ of patients and may become an important therapeutic option in acromegaly $(10,11)$. However, the most recent consensus guidelines for the management of acromegaly suggest for the majority of patients surgery as the first-line therapy, either alone or in combination with medical treatment, conventional radiotherapy and/or radiosurgery (12). The aim of this study was to update the surgical results and the longterm outcome of the largest-ever reported consecutive series of acromegalic patients treated in the Department of Neurosurgery at the University of Erlangen-Nürnberg using the current internationally accepted criteria for biochemical 'cure' of the disease and to compare the results concerning control of disease with previous series using older criteria of cure. 


\section{Patients and methods}

\section{Patient series}

Between December 1982 and December 2001, 688 operations (514 primary transsphenoidal, 28 primary transcranial and 146 secondary (repeat) surgery) in 646 patients harbouring $\mathrm{GH}$-secreting pituitary adenomas were performed in the Department of Neurosurgery of the University of Erlangen-Nürnberg, the majority of them by the senior author (F R). Of these, 634 patients presented with signs and symptoms of acromegaly and 12 with gigantism, ranging in age from 12 to 76 years (mean $42.3 \pm 10.6$ s.D. years). There were 338 females and 306 males (ratio female: male 1.1:1.0). However, patients lacking complete postoperative endocrinological data $(n=10)$, patients mainly referred from abroad, who were lost to followup $(n=5)$, and the patient who died following transsphenoidal surgery, were not included in the evaluation of the endocrinological outcome. Evaluation of the surgical results was performed on 506 patients following primary transsphenoidal, 26 patients following primary transcranial and 140 patients following secondary surgery (672 surgical procedures in 630 patients). The period of follow-up monitoring ranged from 12 to 228 months (mean 146士62 months). During the period of study 48 patients died.

\section{Endocrinological evaluation}

Preoperatively, basal fasting level of GH, IGF-I (determined routinely since 1989), prolactin (PRL), cortisol, gonadotrophins, testosterone, estradiol and thyroid hormones were measured in the serum of all patients. Preoperatively, in $638(95 \%)$ cases an oral glucose tolerance test (OGTT) was performed. In all other cases $(n=34)$ the test was not possible due to severe diabetes mellitus. Postoperatively, OGTT was performed at day 7 in all but one case (patient died at day 4 following surgery) and was repeated at 3 months in 640 of $646(99 \%)$ and then in annual or biannual intervals in 630 of $646(97.5 \%)$ of the cases.

IGF-I levels were routinely available from 1989. Of the 242 surgically treated patients before 1989, in 103 cases the preoperative IGF-I levels could be provided by the referring endocrinologists. For the rest of the patients no preoperative IGF-I levels were available. Postoperatively, in 158 out of 242 patients IGF-I levels were again provided by their referring doctors. For the rest, IGF-I levels were measured by the authors in a later follow-up visit and were correlated to the results of OGTT at 3 months after surgery. Due to incomplete data seven patients had to be excluded from this study.

Pituitary stimulation as a combination of adrenocorticotrophin (ACTH), thyrotrophin-releasing hormone (TRH) and luteinizing hormone (LH)-releasing hormone tests or the short ACTH test alone combined with basal measurements of all other pituitary hormones and with clinical signs and symptoms was used to reveal preoperative pituitary deficiencies. Hormonal deficiencies of the corticotroph and the thyreotroph axis were corrected prior to surgical intervention. Corticosteroids were not given routinely after surgery except in cases of known hypocortisolism. The same tests as performed preoperatively were repeated 7 days after surgery. Further endocrinological and radiological controls were performed at 3 and 12 months following surgery.

Of the 630 patients, $389(61.7 \%)$ were followed up by the authors. Long-term data of all other patients were provided by the referring endocrinologists. Follow-up examinations were held mostly at annual or biannual visits.

The assays used for hormone measurements changed over the very long time period of the study. Between December 1982 and April 1989 RIAs (CIS Isotopendiagnostik; Dreieich, Germany) were used. From May 1989 until December 2000 ELISAs were used (Pharmacia \& Upjohn, Erlangen, Germany). Since December 2000 the luminometric method was used (Immulite; DPC-Biermann, Nauheim, Germany). IGF-I assays became routinely available in 1989. Until February 2000 an RIA was used (Bio-Merieux, Marcy l'Etoile, France). Since then ELISA has been the preferred method of determination (Pharmacia \& Upjohn). For the definition of 'normality' using different GH/IGF-I assays no allowances were made. IGF-I was always evaluated according to the age-related diagrams provided by the manufacturer of the assays.

In the present study, the data were analysed according to the most recent definition of cure resulting from the International Consensus Conferences in Cortina d'Ampezzo 1999 and Monte Carlo 2000 as published by Giustina et al. (13) (Table 1). Early remission was achieved if all three criteria were fulfilled during the endocrinological evaluation 3 months after surgery. Furthermore, the results of the annual or biannual followup visits were analysed to estimate the recurrence rates.

In addition to hormonal evaluation by the mentioned tests, clinical signs and symptoms of hypopituitarism were evaluated by means of a standardised questionnaire and physical examination. In females, assessment of menstrual cycle abnormalities (e.g. oligomenorrhoea or amenorrhoea) and in males, loss of facial and body hair and loss of libido and impotence, combined with low basal levels of gonadotrophins and/or a less than 3-fold increase in LH and a less than 2-fold increase in

Table 1 The most recent broadly accepted definition of biochemical 'cure' of acromegaly resulting from the International Consensus Conference of Cortina d'Ampezzo 1999 (Giustina et al. (13)).

Normalisation of the basal GH level below $2.5 \mu \mathrm{g} / \mathrm{l}$ Suppression of $\mathrm{GH}$ to $<1 \mu \mathrm{g} / \mathrm{l}$ during $\mathrm{OGT}$ IGF-I normal for age and gender 
follicle-stimulating hormone (FSH) after administration of gonadotrophin-releasing hormone led to the diagnosis of secondary hypogonadism. In the case of postmenopausal women, this was diagnosed when the serum gonadotrophins were low or low normal. Secondary adrenal failure was diagnosed in cases of antecedent malaise, circulatory collapse, unexplained vomiting, weight loss and insufficient stimulation of the serum cortisol levels after ACTH administration (e.g. increase in cortisol of less than $7 \mu \mathrm{g} / \mathrm{dl}$ over the basal value or a value of less than $18 \mu \mathrm{g} / \mathrm{dl}$ during ACTH stimulation). Secondary hypothyroidism was associated with constant feeling of coldness, coarsening, seeding of hair, thickening of the skin and low peripheral triiodothyronine and thyroxine with lowered basal thyrotrophin (TSH) and/or insufficient stimulation after TRH administration in the absence of severe non-thyroid illness or of replacement therapy with thyroid hormones for goitre prophylaxis. Postoperative GH deficiency was not assessed in these patients.

\section{Neuropathological examination}

The neuropathological evaluation was performed at the Department of Neuropathology of the University of Erlangen-Nürnberg. All specimens were fixed in 10\% zinc-formalin, embedded in paraffin and stained by the haematoxylin-eosin method. Immunohistochemistry with antibodies against GH, PRL, ACTH, FSH, LH, TSH and the alpha-subunit of the glycoproteins was performed using the avidin-biotin peroxidase method. Electron microscopy was not used routinely.

\section{Surgical treatment}

The vast majority of the surgical procedures $(n=506)$ were performed by the transsphenoidal route. In 26 cases with invasive, asymmetrical suprasellar, retrosellar and/or supraclinoidal parasellar extension, transcranial surgery via a pterional approach was used and only in one case (with an invasive adenoma in the interhemispheric region) was a bifrontal approach required. Combined transsphenoidal and transcranial approaches were used to treat 16 patients.

Secondary (repeat) surgery was carried out exclusively by the transsphenoidal route in 140 patients, mostly referred from other endocrinological and neurosurgical departments for persistence of acromegaly following primary surgery $(n=98)$. In 42 patients the first operation was performed at the authors' department.

\section{Statistical analysis}

Data are presented as means \pm S.D. Statistical analysis of the data concerning the influence of the presence of invasion, tumour size, preoperative GH levels and of the results of the neuropathological evaluation on remission rate was performed using a chi-squared test, Student's $t$-test and analysis of variances (ANOVA). The level of significance was set at $P<0.05$.

\section{Results}

Depending on the growth characteristics, degree and direction of extrasellar expansion, GH-secreting adenomas were classified as microadenomas (tumour diameter $\leq 10 \mathrm{~mm}$ ), macroadenomas (tumour diameter $11-39 \mathrm{~mm}$ ) and giant adenomas (tumour diameter $\geq 40 \mathrm{~mm}$ ). Macroadenomas were further divided into intrasellar tumours (is), parasellar and/or sphenoidal tumours (ps/sphe), suprasellar tumours without visual compromise (s1) and suprasellar tumours with visual compromise (s2).

\section{Primary transsphenoidal surgery}

The overall rate of endocrinological remission in the group of 506 patients undergoing primary transsphenoidal surgery was $57.3 \%$ (290 of 506) with $27 \%$ of the tumours having an invasive character. The best results were achieved in the microadenoma and intrasellar macroadenoma groups with $75.3 \%$ (107 of 142 ) and $74.2 \%$ (78 of 105$)$ respectively, considering all three criteria for biochemical cure. Remission rate tended to drop in the more extensive macroadenomas: $44.5 \%$ (37 of 83 ) for suprasellar tumours without and $33.3 \%$ (8 of 24) for suprasellar tumours with visual compromise and $41.5 \%$ (59 of 142) for tumours with parasellar and/or sphenoidal expansion. In giant adenomas, biochemical cure was achieved only in one case (1 of 10) by surgery alone. An overview of the remission rate in the different categories following

Table 2 An overview of the remission rate in the different categories of tumours following primary transsphenoidal surgery $(n=506)$; $23 \%$ of the tumours were found to be invasive.

\begin{tabular}{|c|c|c|c|c|c|c|c|}
\hline & \multirow[b]{2}{*}{ Microadenomas } & \multicolumn{4}{|c|}{ Macroadenomas } & \multirow[b]{2}{*}{ Giant adenomas } & \multirow[b]{2}{*}{$\Sigma$} \\
\hline & & is & ps/sphe & s1 & s2 & & \\
\hline Number of cases & 142 & 105 & 142 & 83 & 24 & 10 & 506 \\
\hline Remission* rate $(n)$ & $107(75.3 \%)$ & $78(74.2 \%)$ & $59(41.5 \%)$ & 37 (44.6\%) & $8(33.3 \%)$ & $1(10.0 \%)$ & $290(57.3 \%)$ \\
\hline
\end{tabular}

${ }^{*}$ Basal GH $<2.5 \mathrm{ng} / \mathrm{ml}$, OGT GH $<1 \mathrm{ng} / \mathrm{ml}$, normal IGF-I. 
primary transsphenoidal surgery is provided in Table 2 . In a number of patients discrepancies concerning normalisation criteria were observed. Of the 152 patients with persistence of elevated IGF-I levels, in 49 cases (32.2.\%) suppression of $\mathrm{GH}$ to below $1 \mathrm{ng} / \mathrm{ml}$ during OGTT was observed. In the group of patients lacking normalisation of GH secretion during OGTT $(n=64)$, 19 patients $(29.8 \%)$ with normalised IGF-I levels were observed. Even the last group was considered as not being in remission.

\section{Primary transcranial surgery}

Transcranial surgery was performed in only 26 cases, mostly for extensive and invasive asymmetrical lesions extending into the suprasellar area or as a combined approach before or after transsphenoidal surgery. In line with the characteristics of these lesions, the overall remission rate was only $7.7 \%(n=2)$. The transcranial group consisted of suprasellar macroadenomas with visual compromise (s2, $n=16$ ) and giant adenomas $(n=2)$. Transcranial surgery yielded remission rates of $16.2 \%(n=2)$ and $0 \%$ respectively.

\section{Secondary (repeat) surgery}

Re-operations were performed in 140 cases in this series. In this group the overall remission rate was $27.1 \%(n=38)$. In the subgroup of patients $(n=62)$ with non-invasive tumours and an initial GH level below $40 \mu \mathrm{g} / \mathrm{l}$ prior to the first surgical approach, the remission rate was found to be as high as $38.7 \%$ $(n=24)$.

\section{Surgical complications}

Mortality was rare. Only one patient (0.1\%), harbouring a giant adenoma, died on day 4 after surgery due to haemorrhage into the suprasellar tumour parts, which due to invasion of the diaphragm could not be removed by the transsphenoidal approach used in this case. Morbidity was very low: meningitis and cerebrospinal fluid leaks respectively occurred in 1.8 and $0.8 \%$ of the cases respectively. In this series, there were no cranial nerve injuries resulting in permanent neuro-ophthalmological deficits. Carotid artery injury occurred in one patient and was survived without sequelae. The complication rate in repeat transsphenoidal surgery was not significantly different from that found in primary procedures.

\section{Impact of primary surgery on pituitary function}

For the evaluation of the surgical intervention on pituitary function only patients who underwent primary transsphenoidal $(n=506)$ or transcranial $(n=26)$ surgery were taken into consideration. There was evidence of some degree of hypopituitarism preoperatively in 285 of $506(56.3 \%)$ of the primary transsphenoidal and in 20 of $26(76.9 \%)$ patients of the primary transcranial group. Postoperative clinical and endocrinological workup revealed impaired pituitary function in 235 (46.4\%) after 3 months for all patients who underwent transsphenoidal surgery. In contrast, the total amount of patients with endocrine deficits increased following primary transcranial surgery: hypopituitarism was encountered postoperatively in up to 24 (94\%) patients 3 months after surgery. At 3 months following primary transsphenoidal surgery, anterior pituitary function was normalised in 55 (19.3\%), improved in $84(29.4 \%)$, remained unchanged in $141(49.5 \%)$ and worsened in $5(1.8 \%)$ of the 285 patients with some degree of preoperative hypopituitarism. Endocrine deficiencies in patient with normal preoperative pituitary function occurred in 10 of 241 (4.1\%) cases. At 3 months following transcranial surgery, anterior pituitary function was not normalised in any patient but was improved in $3(15 \%)$, remained unchanged in 12 $(60 \%)$ and worsened in $5(25 \%)$ of the 20 patients with preoperative impairment of the pituitary function. In four of the six transcranially operated patients presenting without endocrine deficits, deterioration of the pituitary function was encountered. None of the patients of the primary surgery group presented with diabetes insipidus. Six of the $506(1.1 \%)$ transsphenoidal treated and 3 of the $26(11.5 \%)$ transcranially treated patients developed permanent diabetes insipidus. The results are summarised on Table 3.

Of the 532 patients undergoing primary surgery, hyperprolactinaemia was demonstrated in 182 $(34.2 \%)$ patients. In $71.9 \%$ of these cases $(n=131)$ the PRL levels were found below $150 \mathrm{ng} / \mathrm{ml}$ and in 39 of them the tumour stained positive for PRL. In all but two patients with PRL levels $>150 \mathrm{ng} / \mathrm{ml}$ $(n=49)$ the adenoma stained positive for PRL.

Table 3 An overview of the endocrinology of the patients with impaired preoperative pituitary function. New endocrine deficiencies in patients with normal preoperative pituitary function occurred in 10 of $241(4.1 \%)$ of cases.

\begin{tabular}{lcrr}
\hline & \multicolumn{2}{c}{ Postoperative pituitary function } \\
\cline { 2 - 4 } & Normal & Improved & No change \\
\hline Transsphenoidal surgery $(n=285)$ & $55(19.3 \%)$ & $84(29.5 \%)$ & $141(49.5 \%)$ \\
Transcranial surgery $(n=20)$ & 0 & $3(15.0 \%)$ & $5(1.8 \%)$ \\
\hline
\end{tabular}




\section{Remission rate in invasive tumours}

Pituitary adenomas are considered invasive if they have infiltrated or perforated the normal anatomical confines of the pituitary gland, namely the sellar diaphragm, basal dura, clivus or sphenoidal and cavernous sinuses. Although invasion tends to be more common with increasing tumour size, microadenomas may also have an invasive character and conversely large tumours may reach a considerable size by simply displacing the adjacent anatomical structures without actually invading them. The evaluation of preoperative magnetic resonance imaging (MRI) and intraoperative findings during primary transsphenoidal and transcranial surgery $(n=532)$ yielded the following results concerning the distribution of invasive tumours in this series: 7 of 142 microadenomas (5\%), 124 of 378 macroadenomas $(32 \%)$ and 12 of 12 giant adenomas $(100 \%)$. In this series, the overall remission rate of non-invasive adenomas following primary surgery was $66.5 \%$ and dropped to $23.7 \%$ for invasive tumours. The results of each adenoma group are demonstrated separately in Table 4.

\section{Remission rate and tumour size and secretory activity}

Tumour size was measured from the preoperative MRI (and computed tomography) images and estimated intraoperatively by the surgeon by comparison with microinstruments. A spherical volume distribution was assumed. On the basis of the estimated diameters, tumours were classified into group A with microadenomas less than $10 \mathrm{~mm}(n=142,27 \%)$, group B with macroadenomas more than $10 \mathrm{~mm}$ in diameter $(n=378,70.7 \%)$ and group $\mathrm{C}$ with giant adenomas with more than $40 \mathrm{~mm}$ extension at least in one plane $(n=12,2.2 \%)$. A remission rate of $75.3 \%$ in group A, $48.6 \%$ in group B and $8.3 \%$ in group C was observed. The results are summarised in Table 5. A significant correlation $(r=0.55, P<0.001)$ was found between tumour size and remission rate in acromegaly. But also, tumour size correlated $(r=0.48, P<0.001)$ with the preoperative $\mathrm{GH}$ level particularly in large tumours with clearly elevated hormone levels. The preoperative GH level tended to correlate negatively with the surgical outcome $(r=0.61, P<0.001)$. In patients with preoperative $\mathrm{GH}$ levels of less than
Table 5 A significant correlation was found between tumour size and remission rate in acromegaly. But also, tumour size correlated with the preoperative GH level particularly in large tumours with clearly elevated hormone levels. Values are means \pm S.D.

\begin{tabular}{lccc}
\hline & Microadenoma Macroadenoma Giant adenoma \\
\hline$n$ & $142(27 \%)$ & $378(70.7 \%)$ & $12(2.2 \%)$ \\
Diameter & $2-9$ & $10-37$ & $41-60$ \\
$\quad(\mathrm{~mm})$ & $7.6 \pm 1.75$ & $16.7 \pm 5.6^{+++}$ & $50.9 \pm 9.5^{++}$ \\
$\begin{array}{c}\text { Average } \\
\text { diameter }(\mathrm{mm})\end{array}$ & $1-142$ & $4-357$ & $10-398$ \\
$\begin{array}{c}\mathrm{GH} \text { level } \\
(\mu \mathrm{g} / \mathrm{l})\end{array}$ & $16.4 \pm 15.2$ & $42.6 \pm 38.4^{+++}$ & $102.4 \pm 64.3^{++}$ \\
$\begin{array}{c}\text { Average GH } \\
\text { level }(\mu \mathrm{g} / \mathrm{l})\end{array}$ & $107(75.3 \%)$ & $186(48.6 \%)$ & $1(8.3 \%)$ \\
$\begin{array}{c}\text { Remission } \\
\text { rate }(n)\end{array}$ & & & \\
\hline
\end{tabular}

$10 \mu \mathrm{g} / \mathrm{l}$ the remission rate was as high as $89.5 \%$. If a basal GH level of $50 \mu \mathrm{g} / \mathrm{l}$ is defined as an arbitrary threshold for the secretory activity of an adenoma, then the overall cure rate drops from $74 \%$ in cases with preoperative $\mathrm{GH}$ levels below this threshold to $25 \%$ in cases with preoperative $\mathrm{GH}$ levels above this threshold. No patient with GH level above $125 \mu \mathrm{g} / \mathrm{l}$ could be surgically cured.

\section{Remission rate and neuropathological evaluation}

Since the electron microscopy was not used routinely, it was not possible to evaluate the influence of the ultrastructural characteristics of the lesions on the endocrinological outcome. Therefore only their immunohistochemical profiles in terms of positive staining were taken into consideration. Of the 532 patients who underwent primary transsphenoidal or transcranial surgery, tumour specimens could be obtained in 526 cases. In six cases and due to very small tumours no material could be preserved. Three hundred and forty-seven $(65.9 \%)$ tumours stained positive only for GH. In $159(30.2 \%)$ tumours a dual secretion of GH and PRL was noted. Fourteen $(2.6 \%)$ tumours stained positive for GH and TSH and six (1.1\%) for GH, PRL and TSH. The remission rates were found to differ significantly between the pure GH-secreting and those tumours secreting more than one hormone and was found to be $73.7 \%(n=256), 31.4 \%(n=50), 0 \%$ and $0 \%$ for the four groups respectively.

Table 4 Demonstration of the remission rates in invasive (i.) and non-invasive (n.i.) pituitary adenomas according to tumour size. In this series, the overall remission rate of non-invasive adenomas following primary surgery was $72.2 \%$ and dropped to $21.6 \%$ for invasive tumours.

\begin{tabular}{|c|c|c|c|c|}
\hline & Microadenomas i./n.i & Macroadenomas i./n.i. & Giant adenomas i./n.i. & $\Sigma$ i./n.i. \\
\hline Number of cases & $135 / 7$ & $254 / 124$ & $0 / 12$ & $389 / 143$ \\
\hline Remission* rate $(n)$ & 100/6 (74\%/85\%) & $181 / 24(71.2 \% / 19.3 \%)$ & $0 / 1(0 \% / 8.3 \%)$ & $281 / 31(72.2 \% / 21.6 \%)$ \\
\hline
\end{tabular}

*Basal GH $<2.5 \mathrm{ng} / \mathrm{ml}$, OGT GH $<1 \mathrm{ng} / \mathrm{ml}$, normal IGF-I. 


\section{Recurrence rate}

In the present series, a mean follow-up period of more than 120 months (mean 126 14 months) has been observed. During this period and using all three criteria for the definition of biochemical cure, only two patients $(0.4 \%)$ with recurrent acromegaly presented 3 and 6 years after initial surgery.

\section{Discussion}

The goals of surgical therapy in acromegaly include initial endocrinological remission with normalisation of the dynamic GH secretion pattern as well as normalisation of basal IGF-I to give regression of the signs and symptoms of the disease and prevention of recurrence (long-term remission), performance of selective adenomectomy (preservation of normal pituitary functions) and elimination of mass effects resulting in restoration of normal neurological function.

As a result of the difficulties in defining postoperative endocrinological remission and the variations in criteria used by different investigators (13), the success rates in terms of achievement of these goals vary significantly in the published series from different institutions (Table 6).

In early series, the criterion for remission was a postoperative GH level below $5 \mu \mathrm{g} / \mathrm{l}$. Ross \& Wilson (14) in 1998 analysed the results of 30 published series and yielded an overall 'cure' rate of $56 \%$ in 153 cases. In another multicentre study published in 1987 by Zervas (15) the overall 'cure' rate was 66\% in 1256 cases. Similar results were found in other series published by Losa et al. 1989 (16) and Valdemarsson et al. in 1991 and $2000(17,18)$.
Using the GH response after an oral glucose load and the IGF-I level to assess the effectiveness of surgery, rates of endocrinological remission in the present series did not differ significantly from our previous series published in 1992 (19). In this former series, the overall remission rate was $71 \%$ with a basal $\mathrm{GH}$ level below $5 \mu \mathrm{g} / \mathrm{l}$ as the criterion for endocrinological remission, but dropped significantly to $57 \%$ with a glucose-suppressed GH level below $2 \mu \mathrm{g} / \mathrm{l}$. The use of all three criteria in the present series, including normalisation of basal IGF-I, does not further change the previously reported endocrinological remission rates, as also shown by Tindall et al. 1993 (20), Laws et al. 2000 (21) and Kreutzer et al. 2001 (22). The role of postoperative IGF-I levels in the long-term outcome of the disease has not been fully elucidated yet. Normalisation of IGF-I and clinical improvement were significantly correlated, but in clinical practice often discrepancies concerning these criteria were observed (23). Evaluating the endocrinological outcome in this study, not only could a number of postoperative patients be identified with normal IGF-I levels but still abnormal nadir GH levels after oral glucose but also a number of patients with elevated levels of IGF-I even if during OGTT GH levels could be suppressed to below $1 \mu \mathrm{g} / \mathrm{l}$. Despite the elevation of IGF-I or the abnormal OGTT suppression many of these patients had a favourable long-term outcome concerning control and recurrence of the disease. For the evaluation of the series all these cases were considered as surgical failures. Recent data suggest that the abnormal pattern of GH suppression in patients with normal IGF-I level may be associated with increased risk of disease recurrence in some of them (24). Based on our personal experience in the treatment of acromegalic patients, we feel that even satisfying the most stringent criteria

Table 6 Results of primary transsphenoidal surgery for GH-secreting pituitary adenomas.

\begin{tabular}{|c|c|c|c|c|c|}
\hline Series & No. cases & Total cure rate (\%) & Microadenomas & Macroadenomas & Definition of 'cure' \\
\hline Ross \& Wilson 1988 (14) & 153 & 56 & n.d. & n.d. & $\mathrm{GH}<5 \mu \mathrm{g} / \mathrm{l}$ \\
\hline Losa et al. 1989 (16) & 29 & 55 & n.d. & n.d. & $\mathrm{GH}<1 \mu \mathrm{g} / \mathrm{l}$ and normal IGF-I level \\
\hline \multirow{2}{*}{ Fahlbusch et al. 1992 (19) } & 222 & 57 & 72 & 49 & $\mathrm{GH}<2 \mu \mathrm{g} / \mathrm{l} \mathrm{OGT}$ \\
\hline & & 71 & 81 & 65 & $\mathrm{GH}<5 \mu \mathrm{g} / \mathrm{l}$ \\
\hline Tindall et al. 1993 (20) & 91 & 82 & n.d. & n.d. & $\mathrm{GH}<5 \mu \mathrm{g} / \mathrm{l}$ and/or normal IGF-I level \\
\hline Davis et al. 1993 (36) & 174 & 52 & n.d. & n.d. & $\mathrm{GH} \leq 2 \mu \mathrm{g} / \mathrm{l}$ (basal or OGT) \\
\hline Sheaves et al. $1996(28)$ & 100 & 42 & 61 & 23 & $\mathrm{GH} \leq 2.5 \mu \mathrm{g} / \mathrm{l}$ \\
\hline Abosch et al. 1998 (41) & 254 & 76 & 75 & 71 & $\mathrm{GH}<5 \mu \mathrm{g} / \mathrm{l}$ \\
\hline Freda et al. 1998 (23) & 115 & 61 & 88 & 53 & $\mathrm{GH}<2 \mu \mathrm{g} / \mathrm{I} \mathrm{OGT}$ or normal IGF-I level \\
\hline Swearingen et al. 1998 (4) & 162 & 57 & 91 & 48 & Random GH $<2.5 \mu \mathrm{g} / \mathrm{l}$ \\
\hline Gittoes et al. 1999 (42) & 160 & 64 & 86 & 52 & $\mathrm{GH}<2.5 \mu \mathrm{g} / \mathrm{l}$ or $\mathrm{GH}<1 \mu \mathrm{g} / \mathrm{l}(\mathrm{OGT})$ \\
\hline Ahmed et al. 1999 (39) & 139 & 67 & 91 & 45 & Mean $\mathrm{GH}<2.5 \mu \mathrm{g} / \mathrm{l}$ \\
\hline Laws et al. 2000 (21) & 117 & 67 & 87 & 50.5 & $\begin{array}{l}\mathrm{GH} \leq 2.5 \mu \mathrm{g} / \mathrm{l}, \mathrm{GH} \leq 1 \mu \mathrm{g} / \mathrm{l}, \text { normal } \\
\text { IGF-I level }\end{array}$ \\
\hline Kreutzer et al. 2001 (22) & 57 & 70 & n.d. & n.d. & Normal IGF-I level \\
\hline Beauregard et al. 2003 (1) & 103 & 52 & 82 & 60 & $\begin{array}{l}\text { Basal } \mathrm{GH} \leq 2.5 \mu \mathrm{g} / \mathrm{l}, \mathrm{GH} \leq 1 \mu \mathrm{g} / \mathrm{l} \\
\text { (OGT), normal IGF-I level }\end{array}$ \\
\hline This series & 506 & 57 & 75 & 50 & $\begin{array}{l}\text { Basal } \mathrm{GH} \leq 2.5 \mu \mathrm{g} / \mathrm{l}, \mathrm{GH} \leq 1 \mu \mathrm{g} / \mathrm{l} \\
\text { (OGT), normal IGF-I level }\end{array}$ \\
\hline
\end{tabular}

n.d., not done. 
no definite 'cure' of the disease is achieved. Even following 'successful' surgical treatment, GH levels remain detectable and pulses of GH secretion are not normal in frequency and size (25). In acromegaly the most accurate term to be used is 'safe' GH secretion patterns, meaning relief of symptoms, restoration of normal life expectancy and minimal risk of recurrence of the disease. IGF-I seems to play a very important role in predicting long-term outcome. But more studies are still needed in order to precisely evaluate the value of IGFI levels as a long-term outcome criterion. Together with the development of more sensitive ELISAs in the near future we may then be able to better define 'cure' in acromegalic patients.

The evaluation of the present series led to detection of several predictors of the surgical result, such as tumour size, invasiveness, extrasellar growth, secretory activity and the neuropathological findings. Regarding the growth characteristics of the lesions, microadenomas have a more favourable outcome than macroadenomas, particularly those with extrasellar extension. In microadenomas, a remission rate of as high as $75.3 \%$ could be achieved. With increasing tumour diameter and extrasellar extension, remission drops stepwise to $0 \%$ for giant adenomas. Similar results were found in other published series, as in the outcome analysis of Tindall et al. (20) and Ross \& Wilson (14). The main reason for this drop is the increasing number of invasive growth patterns in larger adenomas. Invasion can be documented either by intraoperative findings, neuroradiological investigations and/or histological examination. Surgical invasion describes the invasive nature of the tumour as recognised during operation, while histological invasion, although more frequent, can only be demonstrated by investigating the anatomical structures in the vicinity of the tumour. In up to $80 \%$ of the cases, dural invasion can be detected, when the basal dura is thoroughly investigated $(26,27)$. In this series, the overall remission rate of non-invasive adenomas was $66.5 \%$ and dropped to $23.7 \%$ for invasive tumours. Also, for transcranial surgery increased invasiveness of the tumour is the main reason for incomplete tumour resection and persistent disease.

The secretory activity of the adenoma also influences the response to surgical therapy, as observed in several published series $(14,20,28)$. Various thresholds of preoperative basal $\mathrm{GH}$ levels between 40 and $70 \mu \mathrm{g} / \mathrm{l}$ have been proposed. Preoperative GH levels above these values have an inverse relationship with the likelihood of biochemical remission following surgery. In our previously published series we observed that this inverse relationship has an almost linear character. In the present series, this linear relationship was confirmed.

Only one patient died in this series, due to haemorrhage of the suprasellar parts of an only partially removed giant adenoma by a transsphenoidal route. Ross \& Wilson reviewed the operative complications in 30 published surgical series and estimated an operative mortality rate of $1.04 \%$ (14). Due to specific precautions taken in the high-risk group of acromegalic patients, the complication rate in the presented series was comparable to that of non-acromegalic patients undergoing transsphenoidal surgery for other types of pituitary adenomas. Preoperative evaluation included assessment of cardiac function, blood pressure, respiratory function and metabolic disturbances. Morphological abnormalities, such as macroglossia and the enlargement of the jaw were taken into consideration. In several cases, fibre-optic endotracheal intubation was necessary and many patients with severe sleep apnoea were postoperatively monitored in the intensive care unit. All these problems must be carefully managed throughout the perioperative period in order to keep the complication rate as low as possible. In cases of markedly reduced general condition, short-term medical treatment with octreotide should be considered, which has proven very helpful in bringing the patient to a better condition before surgery $(29,30)$.

Postoperative pituitary deficiencies, particularly panhypopituitarism, are considered dreaded complications of pituitary surgery because they dramatically affect the patient's quality of life by necessitating hormonal substitution therapy and lead to increased mortality. Following the introduction of transsphenoidal microsurgery in the management of patients with pituitary tumours, selective adenomectomy was aimed at, implying preservation of as much normal pituitary tissue as possible. Several studies demonstrated that preservation of pituitary tissue was associated with no further loss of pituitary function in the majority of patients. Only recently, several groups reported that impaired pituitary function could actually be restored by selective surgical resection of the adenoma (31-33). This observation could be confirmed in this study in which a large patient material was homogeneously treated by the same surgical techniques and evaluation in one laboratory. Residual anterior pituitary function was more frequently preserved after transsphenoidal surgery $(49.5 \%)$ and could even be normalised or improved in $48.7 \%$ of cases with preoperative endocrine deficiencies. In contrast to most reports in the literature and despite surgical manipulations necessary to remove all tumour parts, only a moderate increase in anterior pituitary deficiency $(4.1 \%)$ was observed as an untoward effect of the operation.

The frequency of tumour recurrence is strongly associated with the remission criteria used. It is paramount to distinguish between postoperative normalisation of GH secretion using all three criteria and those cases with lower postoperative basal GH levels but inadequate response to OGTT and/or abnormal IGF-I levels. Using a postoperative basal $\mathrm{GH}$ below $5 \mu \mathrm{g} / \mathrm{l}$ as the remission criterion, the overall 'recurrence' rate in 61 patients was $7 \%$ over a mean follow-up period 
of 6 years (19). Similar results were published by Losa et al. (16) and Arafah et al. (34). However, using suppression of $\mathrm{GH}$ levels below $2.0 \mu \mathrm{g} / \mathrm{l}$ as the criterion, long-term remission can be achieved as observed by our group in 1991 (35). In other published series, rates of recurrences up to $17.8 \%$ are encountered using other criteria for biochemical cure (36). In the present series, a mean follow-up period of more than 10 years has been observed. During this period and using all three criteria for biochemical cure, only two patients $(0.4 \%)$ with recurrent acromegaly presented 3-6 years after initial surgery. This fact stresses the paramount importance of stringent endocrinological remission criteria in acromegaly.

The management of patients with persistent acromegaly after the first operation is a matter of ongoing discussion. Several meetings have been held to obtain a consensus about how these patients should ideally be treated. All treatment modalities concerning this disease have been discussed in detail. Many of these patients are candidates for repeat surgery. Re-exploration was found to be particularly successful in those cases in which neither surgical nor histological invasion could be demonstrated during the first surgery. In this series, re-explorations have been performed in a number of selected cases, mainly in patients with MRI studies that demonstrated residual adenomatous tissue. As expected, the overall remission rate was worse than in the primary surgery group, at $27.1 \%$. Nevertheless, a remission rate of $38.7 \%$ could be achieved in patients with non-invasive tumours and an initial GH level below $40 \mu \mathrm{g} / \mathrm{l}$ prior to the first surgical approach. To evaluate the effectiveness of secondary transnasal microsurgery, 28 patients with persistent or recurrent acromegaly were analysed by Abe \& Ludecke in 1998 (37). The overall endocrinological remission rate was found to be $57.1 \%$ (16 of 28 patients) without serious morbidity and no mortality. Kurosaki et al. (38) reported even higher remission rates: overall remission $60 \%$, remission in transnasally respectable tumours $81.3 \%$. The absence of major surgical complications and significant endocrinological deterioration of other pituitary functions combined with the possibility of long-term control of the disease supports re-exploration as a treatment option in a number of selected patients with persistent acromegaly.

The results in this series, once more strongly support the role of surgery as the primary management option of acromegalic patients. Surgery is very efficacious in restoring normal $\mathrm{GH}$ secretion patterns, acts rapidly and carries a low therapy-associated morbidity. It is also clear that surgical experience, skill and knowledge play an important role in how successful the primary surgery is $(39,40)$. The results presented above concern only those series published by authors with major expertise in this field and cannot be achieved by surgeons with little experience in pituitary surgery. Supraregional specialisation in a few neurosurgical centres with equally experienced endocrinologists and laboratory staff may lead to even better surgical results in acromegaly.

\section{Acknowledgements}

We thank all endocrinological colleagues for their confidence and cooperation in the mutual treatment of our patients.

\section{References}

1 Beauregard C, Truong U, Hardy J \& Serri O. Long-term outcome and mortality after transsphenoidal adenomectomy for acromegaly. Clinical Endocrinology 200358 86-91.

2 Orme SM, McNally RJ, Cartwright RA \& Belchetz PE. Mortality and cancer incidence in acromegaly: a retrospective cohort study. United Kingdom Acromegaly Study Group. Journal of Clinical Endocrinology and Metabolism $1998 \quad \mathbf{8 3}$ $2730-2734$.

3 Rajasoorya C, Holdaway IM, Wrightson P, Scott DJ \& Ibbertson HK. Determinants of clinical outcome and survival in acromegaly. Clinical Endocrinology 1994 41 95-102.

4 Swearingen B, Barker FG II, Katznelson L, Biller BM, Grinspoon S, Klibanski A, Moayeri N, Black PM \& Zervas NT. Long-term mortality after transsphenoidal surgery and adjunctive therapy for acromegaly. Journal of Clinical Endocrinology and Metabolism $1998833419-3426$.

5 Bates AS, Van't Hoff W, Jones JM \& Clayton RN. An audit of outcome of treatment in acromegaly. Quarterly Journal of Medicine $199386293-299$.

6 Ayuk J, Stewart SE, Stewart PM \& Sheppard MC. Long-term safety and efficacy of depot long-acting somatostatin analogs for the treatment of acromegaly. Journal of Clinical Endocrinology and Metabolism $2002874142-4146$.

7 Bevan JS, Atkin SL, Atkinson AB, Bouloux PM, Hanna F Harris PE, James RA, McConnell M, Roberts GA, Scanlon MF, Stewart PM, Teasdale E, Turner HE, Wass JA \& Wardlaw JM. Primary medical therapy for acromegaly: an open, prospective, multicenter study of the effects of subcutaneous and intramuscular slow-release octreotide on growth hormone, insulin-like growth factor-I, and tumor size. Journal of Clinical Endocrinology and Metabolism $2002 \mathbf{8 7} 4554-4563$.

8 Newman CB. Medical therapy for acromegaly. Endocrinology and Metabolism Clinics of North America 199928 171-190.

9 Newman CB, Melmed S, Snyder PJ, Young WF, Boyajy LD, Levy R, Stewart WN, Klibanski A, Molitch ME \& Gagel RF. Safety and efficacy of long-term octreotide therapy of acromegaly: results of a multicenter trial in 103 patients - a clinical research center study. Journal of Clinical Endocrinology and Metabolism $1995 \mathbf{8 0}$ $2768-2775$.

10 Paisley AN, Trainer PJ \& Drake WM. The place of pegvisomant in the acromegaly treatment algorithm. Growth Hormone and IGF Research 200414 (Suppl A) S101-S106.

11 Trainer PJ, Drake WM, Katznelson L, Freda PU, Herman-Bonert V, Van Der Lely AJ, Dimaraki EV, Stewart PM, Friend KE, Vance ML, Besser GM, Scarlett JA, Thorner MO, Parkinson C, Klibanski A, Powell JS, Barkan AL, Sheppard MC, Malsonado M, Rose DR, Clemmons DR, Johannsson G, Bengtsson BA, Stavrou S, Kleinberg DL, Cook DM, Phillips LS, Bidlingmaier M, Strasburger CJ, Hackett S, Zib K, Bennett WF \& Davis RJ. Treatment of acromegaly with the growth hormone-receptor antagonist pegvisomant. New England Journal of Medicine $2000 \mathbf{3 4 2}$ 1171-1177.

12 Melmed S, Casanueva FF, Cavagnini F, Chanson P, Frohman L, Grossman A, Ho K, Kleinberg D, Lamberts S, Laws E, Lombardi G, Vance ML, Werder KV, Wass J \& Giustina A. 
Guidelines for acromegaly management. Journal of Clinical Endocrinology and Metabolism 200287 4054-4058.

13 Giustina A, Barkan A, Casanueva FF, Cavagnini F, Frohman L, Ho K, Veldhuis J, Wass J, Von Werder K \& Melmed S. Criteria for cure of acromegaly: a consensus statement. Journal of Clinical Endocrinology and Metabolism 200085 526-529.

14 Ross DA \& Wilson CB. Results of transsphenoidal microsurgery for growth hormone-secreting pituitary adenoma in a series of 214 patients. Journal of Neurosurgery $1988 \mathbf{6 8} 854-867$.

15 Zervas NT. Multicenter surgical results in acromegaly. In Growth Hormone, Growth Factors and Acromegaly, pp 253-257. Ed. DK Ludecke. New York: Raven Press, 1987.

16 Losa M, Oeckler R, Schopohl J, Muller OA, Alba-Lopez J \& Von Werder K. Evaluation of selective transsphenoidal adenomectomy by endocrinological testing and somatomedin-C measurement in acromegaly. Journal of Neurosurgery 198970 561-567.

17 Valdemarsson S, Bramnert M, Cronquist S, Elner A, Eneroth CM, Hedner P, Lindvall-Axelsson M, Nordstrom CH \& Stromblad LG. Early postoperative basal serum GH level and the GH response to TRH in relation to the long-term outcome of surgical treatment for acromegaly: a report on 39 patients. Journal of Internal Medicine $199123049-54$.

18 Valdemarsson S, Ljunggren S, Bramnert M, Norrhamn O \& Nordstrom $\mathrm{CH}$. Early postoperative growth hormone levels: high predictive value for long-term outcome after surgery for acromegaly. Journal of Internal Medicine 2000 247 640-650.

19 Fahlbusch R, Honegger J \& Buchfelder M. Surgical management of acromegaly. Endocrinology and Metabolism Clinics of North America 199221 669-692.

20 Tindall GT, Oyesiku NM, Watts NB, Clark RV, Christy JH \& Adams DA. Transsphenoidal adenomectomy for growth hormone-secreting pituitary adenomas in acromegaly: outcome analysis and determinants of failure. Journal of Neurosurgery $1993 \mathbf{7 8}$ 205-215.

21 Laws ER, Vance ML \& Thapar K. Pituitary surgery for the management of acromegaly. Hormone Research 200053 (Suppl 3) $71-75$.

22 Kreutzer J, Vance ML, Lopes MB \& Laws ER Jr. Surgical management of GH-secreting pituitary adenomas: an outcome study using modern remission criteria. Journal of Clinical Endocrinology and Metabolism $2001864072-4077$.

23 Freda PU, Wardlaw SL \& Post KD. Long-term endocrinological follow-up evaluation in 115 patients who underwent transsphenoidal surgery for acromegaly. Journal of Neurosurgery $1998 \mathbf{8 9}$ 353-358.

24 Freda PU, Nuruzzaman AT, Reyes CM, Sundeen RE \& Post KD. Significance of 'abnormal' nadir growth hormone levels after oral glucose in postoperative patients with acromegaly in remission with normal insulin-like growth factor-I levels. Journal of Clinical Endocrinology and Metabolism 200489 495-500.

25 Peacey SR, Toogood AA, Veldhuis JD, Thorner MO \& Shalet SM. The relationship between 24-hour growth hormone secretion and insulin-like growth factor I in patients with successfully treated acromegaly: impact of surgery or radiotherapy. Journal of Clinical Endocrinology and Metabolism 200186 259-266.

26 Ahmadi J, North CM, Segall HD, Zee CS \& Weiss MH. Cavernous sinus invasion by pituitary adenomas. AJR. American Journal of Roentgenology $1986146257-262$.

27 Buchfelder M, Fahlbusch R, Adams EF, Kiesewetter F \& Thierauf P. Proliferation parameters for pituitary adenomas. Acta Neurochirurgica. Supplement $1996 \mathbf{6 5} 18-21$.

28 Sheaves R, Jenkins P, Blackburn P, Huneidi AH, Afshar F, Medbak S, Grossman AB, Besser GM \& Wass JA. Outcome of transsphenoidal surgery for acromegaly using strict criteria for surgical cure. Clinical Endocrinology $1996 \mathbf{4 5} 407-413$.

29 Abe T \& Ludecke DK. Effects of preoperative octreotide treatment on different subtypes of $90 \mathrm{GH}$-secreting pituitary adenomas and outcome in one surgical centre. European Journal of Endocrinology $2001145137-145$.

30 Kristof RA, Stoffel-Wagner B, Klingmuller D \& Schramm J. Does octreotide treatment improve the surgical results of macro-adenomas in acromegaly? A randomized study. Acta Neurochirurgica 1999141 399-405.

31 Arafah BM, Brodkey JS, Manni A, Velasco ME, Kaufman B \& Pearson $\mathrm{OH}$. Recovery of pituitary function following surgical removal of large nonfunctioning pituitary adenomas. Clinical Endocrinology $198217213-222$.

32 Arafah BM, Harrington JF, Madhoun ZT \& Selman WR. Improvement of pituitary function after surgical decompression for pituitary tumor apoplexy. Journal of Clinical Endocrinology and Metabolism 199071 323-328.

33 Nelson AT Jr, Tucker HS Jr \& Becker DP. Residual anterior pituitary function following transsphenoidal resection of pituitary macroadenomas. Journal of Neurosurgery 198461 577-580.

34 Arafah BM, Rosenzweig JL, Fenstermaker R, Salazar R, McBride CE \& Selman W. Value of growth hormone dynamics and somatostatin C (insulin-like growth factor I) levels in predicting the long-term benefit after transsphenoidal surgery for acromegaly. Journal of Laboratory and Clinical Medicine 1987109 346-354.

35 Buchfelder M, Fahlbusch R, Schott W \& Honegger J. Long-term follow-up results in hormonally active pituitary adenomas after primary successful transsphenoidal surgery. Acta Neurochirurgica. Supplement $19915372-76$.

36 Davis DH, Laws ER Jr, Ilstrup DM, Speed JK, Caruso M, Shaw EG, Abboud CF, Scheithauer BW, Root LM \& Schleck C. Results of surgical treatment for growth hormone-secreting pituitary adenomas. Journal of Neurosurgery $1993 \mathbf{7 9} 70-75$.

37 Abe T \& Ludecke DK. Recent results of secondary transnasal surgery for residual or recurring acromegaly. Neurosurgery $1998 \mathbf{4 2}$ 1013-1021; Discussion 1021-1022.

38 Kurosaki M, Luedecke DK \& Abe T. Effectiveness of secondary transnasal surgery in GH-secreting pituitary macroadenomas. Endocrine Journal 200350 635-642.

39 Ahmed S, Elsheikh M, Stratton IM, Page RC, Adams CB \& Wass JA. Outcome of transsphenoidal surgery for acromegaly and its relationship to surgical experience. Clinical Endocrinology 1999 $50561-567$.

40 Lissett CA, Peacey SR, Laing I, Tetlow L, Davis JR \& Shalet SM. The outcome of surgery for acromegaly: the need for a specialist pituitary surgeon for all types of growth hormone $(\mathrm{GH})$ secreting adenoma. Clinical Endocrinology 1998 49 653-657.

41 Abosch A, Tyrrell JB, Lamborn KR, Hannegan LT, Applebury CB \& Wilson CB. Transsphenoidal microsurgery for growth hormone-secreting pituitary adenomas: initial outcome and longterm results. Journal of Clinical Endocrinology and Metabolism $1998833411-3418$.

42 Gittoes NJ, Sheppard MC, Johnson AP \& Stewart PM. Outcome of surgery for acromegaly - the experience of a dedicated pituitary surgeon. QJM $199992741-745$.

Received 4 October 2004

Accepted 10 December 2004 